\title{
How a Rural School Reforms Itself and Develops
}

\author{
Chiotelis Ioannis $^{1}$, Theodoropoulou Maria ${ }^{2}$, Birbas George ${ }^{3}$ \\ ${ }^{1}$ Experimental High School of University of Patras, Patras, Greece \\ ${ }^{2}$ Department of Primary Education, University of Patras, Patras, Greece \\ ${ }^{3} 1^{\text {st }}$ Junior High School of Pyrgos, Ili, Greece
}

\section{Email address:}

johnchiotelis@yahoo.gr (Chiotelis I.), mariatheodoropoulou@ymail.com (Theodoropoulou M.), georgebirbas@gmail.com (Birbas G.)

\section{To cite this article:}

Chiotelis Ioannis, Theodoropoulou Maria, Birbas George. How a Rural School Reforms Itself and Develops. International Journal of Secondary Education. Vol. 6, No. 1, 2018, pp. 1-4. doi: 10.11648/j.ijsedu.20180601.11

Received: October 25, 2017; Accepted: November 13, 2017; Published: January 26, 2018

\begin{abstract}
Schools are vital organizations adequate under constant changes, reformations and developments. Teachers, students and parents all contribute into these changes materializing primitive envisions. Especially, a rural school can reform rapidly into a highly developing school. We can mention the High School of Pelopio, a rural school that achieved some of its pronounced educational goals. Teachers' and administration's vision for a new school began by encouraging teachers to participate into educational meetings, conferences and developing courses. Additionally, groups of students were organized to prepare several projects according to their interests. We can mention the Astronomy group, the Environmental group and the Drama group. Accordingly, we invested on extroversion and presentation of projects. Astronomy nights, Environmental events and Theatric performances were some activities that joined our school with the local society, parents and communities. Furthermore, students revealed a remarkable interest about sciences and culture. As a result they took part into several contests and managed to win a European Award. Mainly, we noticed an interesting reformation in our classrooms. Apart from the growing interest we observed that students and parents regarded school via a new prospective and under different philosophy.
\end{abstract}

Keywords: Rural School, Educational Policy, Government, Applied Innovation, Research in Classroom

\section{Introduction}

How can we organize and reform a rural school? Designing a long period action plan can help a school? How can we implement theoretical predictions into real school environment and evaluate our findings? This is actually what we tried to do at General High School of Pelopio, a rural school. It is well known that teachers have to participate into educational conferences and courses (Baird and Fensham 1991). Meetings and courses are crucial for the overall progress and development of teachers (Shannon and Twale 1998). New trends in education had to be spread into a rapidly changing world (Tillema 1994). Modern educators and teachers are expressing a growing demand for lifelong learning programs (Hobson 2002). Additionally, all new trends must be implemented into classrooms and embodied in the traditional curriculum (Helsby 1995). In parallel students must accept and incubate modern pedagogical methods (Finn 1998). Working in groups, consisting working teams, preparing projects and presenting results are some of the new aspects of education (Cohen 1994). On the other hand, excellence groups (Howley 1989) and students' contests (Verhoeff 1997), seems to gain an important part of nowadays educational system. Furthermore, extroversion of knowledge gradually becomes a goal for many schools (Holland 1987). Astronomical and environmental events (generally science courses), cultural performances (theater) are of high educational content. But the question is how we can implement all these aspects into daily educational practice. We tried to apply some of these educational trends into a rural school (General High School of Pelopio) and we observe some remarkable results.

\section{Experimentation}

We began thinking and organizing a fully integrated plan in order to face the problems that occurred in the General High School of Pelopio. We mainly had problems on rising 
students' interest, provoke curiosity, as well some disciplinary matters. Additionally, our school wished to develop extroversion and come closer to local communities. According to these major needs, we set an action plan. Our plan was based on lifelong learning, implementation, group working, production of educational material, extroversion, seminars, educational and cultural events, participation in contests, evaluation and feedback.

\section{Teacher's Constant Learning}

First of all in order to face the problems we realized that teachers had to be educated and trained on new pedagogical and didactic trends (Day 1999). Teachers were encouraged to participate to several training and learning activities. During the first stages of our action plan teachers were educated mainly on new education trends, educational scenarios, ICT implementation in classrooms, modern pedagogical trends and new approaches in daily school life. It was clearly understood that traditional pedagogical methods were inefficient. On contrary whenever a new pedagogical method was applied a rising interest was observed. Teachers also appear more willing to test new approaches. As a result of all these activities we realized how important is for educators to attend training activities and programs. New prospective occurred and new methods applied in classrooms. This was the first step of a school that learns, evolves and develops.

\section{Implementation}

Secondly, teachers were encouraged to produce educational content. Educational scenarios were developed, learning materials ware produced and working groups organized. We introduced and encouraged a new innovative idea of organizing student groups with special skills and responsibilities (Johnson 1990). For example, the Event Organizing Group, the Promotion Group, the Media (e.g. video) Producing Group, the Drama and Astronomical Team were some of the most active groups. We uploaded most of the produced educational material and scenarios on electronic means (e.g. our website), while the working groups started producing projects and events. A group of teachers was responsible for each working group. They were setting final goals, organizing their working plan, scheduling meetings and evaluating their progress. We tried all steps of the working groups to be based on educational scenarios. This parameter was also an important aspect of a constant learning school (Schank 1994). We detected and evaluated all steps, extracting important conclusions of how a school can become a working community. Additionally, the educational material and scenarios seem to encourage students to further search for knowledge. As all this educational materials were available on the web, educators and teachers found additional teaching tools.

\subsection{Excellence and Contests}

A second step to our action plan was excellence, focusing mainly on contests (Bishop 1991). We realized that participating on National or International Contests was really a unique opportunity to raise the interest and competiveness of our students. We can refer to the most successful attempt, the «Odysseus» Contest. This contest was about Astronomy and co-evolution of life in space. Winning the contest was not our initial goal; instead we were mainly interested on developing a progressive educational pathway (Jacobson 2006). First of all we organized a team consisting of almost ten students interested in Astronomy. We scheduled some standard meeting dates, but we met each other mainly out of schedule. Because of the strict school curriculum we had to communicate a lot through electronic means (e.g. Skype). All these state problems and aspects are interesting parameters of how a school learns to work in groups, communicate and develop a project (Garmston 2013). We learned that ICT are absolutely necessary tools for education.

\subsection{Astronomical Event}

Developing our Astronomy project, we realized that we needed some hands on experience, observation knowledge and support by experts. These realizations were important on organizing the first Astronomical event in our school's region open to local community. The event was a result of an excellent collaboration between several working groups, teachers and authorities. The event-organizing group supported the whole action, the promotion group, the media group and astronomical team also took great responsibilities. Teachers from our school participated in several parts of the event, while we had the support of the Municipality of A. Olympia and the 7th Ephorate of Prehistoric and Classical Ancients (EPCA) of A. Olympia. We operated remote telescopes from distance, a professor from University of Patras gave Lecture about the Universe and finally we observed astronomical objects by telescopes. All these activities raised the interest of students and revealed a new orientation in learning procedure for our school. Local communities and authorities came closer to our school and we learned how to expand our audience (Hanifan 1916). We had now a strong team willing to work harder for our contest project.

From this point and on the final title of our project was clear. We decided to work on plants attitude and color on another planet. The contest's demand was a clearly defined scientific question, fully developed and answered through experimental and bibliographic justification. Although the difficulties, we managed to win the National part of the contest on March 2013 and the European part of the contest on April 2013. Of course this was the first step of a working methodology. Although it seems that our main goal was the win of the Contest this is not absolutely accurate. We initially tried to intrigue and provoke students to take part to all the related activities. It was the same with the participation of an environmental Contest and also with the drama performances of our school. Furthermore, we realized that extroversion events are extremely important for the educational practice (Elmore 2007). 


\subsection{Environmental Event}

We followed up with an environmental event, which was actually an ecological meeting. This event combined lectures by professors of the University of Patras (another important parameter is growing a standard collaboration with higher education foundations), hands on activities (experimentation related to chemical effects on environment), speeches by market representatives and groups of volunteers. This was also an open event to local community. Apart from this aspect students learned many about connection between education and market especially on the agricultural field (Clark 1983). Additionally, volunteerism presented to students as a part of environmental protection part (Goldberg 1998). All these aspects were highly educative for students and local community, while a rural school approaches the day life of local society (mainly agricultural) from many aspects (scientific, economic, activism). On the other hand this was our second extroversion event. Our working groups continued developing and performing even more professional. Doubtless an important parameter of the constant learning school is assigning important responsibilities to students (Ames 1992).

\subsection{Innovative Approaches}

In parallel we introduced some innovative approaches in every day teaching practice. Real time (synchronous) video conferences were implemented on several lessons (Murphy \& Coffin 2003). An interview from the researcher Michael Tsambas at Lyon France and a couple of virtual visits to CERN were some of our distant learning attempts. Additionally, we increased the use of ICT on daily teaching practice. Whole lesson were presented digitally, while experiments were combined with electronic means e.g. we used augmented reality applications (Kaufmann 2003) and Kinect camera for detecting movement and air presenting (Hsu 2011). In all these actions students' working groups organized almost the whole activities. We realized that students were feeling important in participating actively, while they count the success of the event as their personal success. This is also a remarkable point as we often focused on students with low learning expectations but exceptional technical skills giving them responsible roles on all events Furthermore, we also gained important profits on the disciplinary section. Students felt that a well organized and extrovert school is not only a matter of strict rules and punishments, but mainly a school that develops healthy relationships between all members (students, teachers, parents, local community).

\section{Follow up}

General High School of Pelopio continued its actions by supporting important events. Municipality of A. Olympia asked for supporting events related to Summer Olympic Games of London U.K., 2012 and Winter Olympic Games Sotsi Russia, 2014. Furthermore, students and teachers participated into several educational projects related to Science, History and culture. We can refer to the interdisciplinary project «Mythology of the Night Sky» where all the myths related to constellations were inquired. A visit to Athens Planetarium (Eugenides Foundation) in combination with a visit to Archeological museum of Acropolis contributed in the collection of evidence. According to this action we learned that an important part of education is the hands on activities (Hofstein \& Lunetta 2004) and evidence collecting visits to science institutes, history and culture centers (HooperGreenhill 1999).

\section{Conclusions}

According to our action plan we conclude that first of all it is of high importance schools to organize and plan their actions in long term (Sniehotta, Schwarzer, Scholz, $\&$ Schüz 2005). We realized that planning a three or four years plan will be absolutely beneficial for achieving goals and upgrading educational practices. This also reveals that an essential evaluation can only be performed after a long period (3-5 years) of actions and activities. Secondly we confirmed the importance of lifelong training for teachers and educators. Doubtless, participating in educational seminars, conferences and training meetings allow teachers to be always informed about new educational trends (Day 1999). Implementing all these compulsory methods in classrooms turns out to be extremely positive for students. Furthermore, organizing extroversion events by entrusting critical responsibilities to students was also one of our positive remarks (Elmore 2007). We observed that all these events joined teachers, students and local community together. Science and culture came closer to students and local society, while the interest of students rose remarkable. All these events include the element of collaboration and cooperation between several partners and promote our basic goal of knowledge diffusion. Additionally, participation in contests is another crucial parameter (Bishop 1991). Healthy competiveness between students and schools can only offer benefits to all participants. Winning a contest is not the key. We are mainly interested in the whole progress and steps of contest. We wish students to take part, work, search, compose papers and support publicly their projects. Of course a won contest satisfies students and encourage them for new tries. Another remarkable conclusion is the importance of educational scenarios, material and content (Jacobson 2006). All these produced objects are really useful for planning and orienting bigger action plans. Furthermore if all these educational objects are uploaded in websites, everyone can easily access and use them. Finally, we can claim that each step was an evaluated progress of a previous one, helping us to achieve goals and milestones. This is how a school learns by itself and by others. 


\section{References}

[1] Ames, C. (1992). Classrooms: Goals, structures, and student motivation. Journal of educational psychology, 84(3), 261.

[2] Baird, J. R., Fensham, P. J., Gunstone, R. F. and White, R. T. (1991), The importance of reflection in improving science teaching and learning. J. Res. Sci. Teach., 28: 163-182. doi: $10.1002 /$ tea.3660280207.

[3] Bishop, J. H. (1991). A strategy for achieving excellence in secondary education: The role of state government. CAHRS Working Paper Series, 356.

[4] Clark, D. H. (1983). How Secondary School Graduates Perform in the Labor Market. A Study of Indonesia. World Bank Staff Working Papers Number 615. World Bank Publications, PO Box 37525, Washington, DC 20013.

[5] Day, C. (Ed.). (1999). Developing teachers: The challenges of lifelong learning. Psychology Press.

[6] Elizabeth G. Cohen, Restructuring the Classroom: Conditions for Productive Small Groups, Review of Educational Research, Spring 1994 vol. 64 no. 1 1-35 DOI: $10.3102 / 00346543064001001$.

[7] Elmore, R. F. (2007). School reform from the inside out: Policy, practice, and performance. Cambridge, MA: Harvard Education Press.

[8] Finn, B, Australian Education Council Review Committee1991, Young people's participation in postcompulsory education and training: report of the Australian Education Council Review Committee [Finn review], Australian Government Publishing Service, Canberra.

[9] Garmston, R. J., \& Wellman, B. M. (2013). The adaptive school: A sourcebook for developing collaborative groups. Rowman \& Littlefield Publishers.

[10] Goldberg, M. F. (1998). How to design an advisory system for a secondary school. ASCD.

[11] Hofstein, A., \& Lunetta, V. N. (2004). The laboratory in science education: Foundations for the twenty-first century. Science education, 88(1), 28-54.

[12] Hanifan, L. J. (1916). The rural school community center. Annals of the American Academy of political and Social Science, 67, 130-138.

[13] Helsby Gill, Teachers' Construction of Professionalism in England in the 1990s, Journal of Education for Teaching: International research and pedagogy, Volume 21, Issue 3, 1995 pages 317-332 DOI: 10.1080/ 02607479550038536.

[14] Hobson Andrew J., Student Teachers' Perceptions of Schoolbased Mentoring in Initial Teacher Training (ITT) Mentoring
\& Tutoring: Partnership in Learning Volume 10, Issue 1, 2002 pages 5-20 DOI: 10.1080 /13611260220133117.

[15] Holland, Alyce, and Thomas Andre. "Participation in extracurricular activities in secondary school: What is known, what needs to be known?" Review of Educational Research 57.4 (1987): 437-466.

[16] Hooper-Greenhill, E. (Ed.). (1999). Museum, media, message. Psychology Press.

[17] Howley Aimee, The progress of gifted students in a rural district that emphasized acceleration strategies, Roeper Review, Volume 11, Issue 4, 1989 pages 205-207, DOI: $10.1080 / 02783198909553211$.

[18] Hsu, H. M. J. (2011). The potential of kinect in education. International Journal of Information and Education Technology, 1(5), 365-370.

[19] Jacobson, M. J., \& Wilensky, U. (2006). Complex systems in education: Scientific and educational importance and implications for the learning sciences. The Journal of the learning sciences, 15(1), 11-34.

[20] Johnson, D. W., \& Johnson, R. T. (1990). Social skills for successful group work. Educational leadership, 47(4), 29-33.

[21] Kaufmann, H. (2003). Collaborative augmented reality in education. Institute of Software Technology and Interactive Systems, Vienna University of Technology.

[22] Murphy, E., \& Coffin, G. (2003). Synchronous communication in a web-based senior high school course: Maximizing affordances and minimizing constraints of the tool. The American Journal of Distance Education, 17(4), 235-246.

[23] Schank, R. C. (1994). Goal-based scenarios: A radical look at education. The Journal of the Learning Sciences, 3(4), 429453.

[24] Shannon David M., Darla J. Twale and Mathew S. Moore TA Teaching Effectiveness: The Impact of Training and Teaching Experience, The Journal of Higher Education Vol. 69, No. 4 (Jul. - Aug., 1998), pp. 440-466.

[25] Sniehotta, F. F., Schwarzer, R., Scholz, U., \& Schüz, B. (2005). Action planning and coping planning for long-term lifestyle change: theory and assessment. European Journal of Social Psychology, 35(4), 565-576.

[26] Tillema H. H., Training and professional expertise: Bridging the gap between new information and pre-existing beliefs of teachers, Teaching and Teacher Education, Volume 10, Issue 6, November 1994, Pages 601-615, DOI: 10.1016/0742051X(94)90029-9.

[27] Verhoeff, T., The role of competitions in education, Future World: Educating for the 21st Century (1997). 